\title{
Rank Power Analysis For Comparative Strength Of Professional Sports Franchises
}

\author{
K. Paul Yoon, Fairleigh Dickinson University, USA \\ Mohammad Sedaghat, Fairleigh Dickinson University, USA
}

\begin{abstract}
Major professional sports teams are nowadays complex businesses, intrinsically concerned with matters of economics and finance. Performances of each teams and each franchises vary greatly. This paper makes comparative performance analyses for four profession franchises in North America. Four financial measures are chosen to represent team performances: attendance, revenue, payroll, and profit. First, the box-plot was utilized to measure the spread of the power (wealth) of each league with respect to each measures. Second, the rank-power distribution was used to visualize the team's relative standings in each measures and in each franchises. Most team performances were observed to follow the Pareto principle: few teams scored very high (significant few); large numbers of teams scored very low (trivial many). These qualitative findings can be a useful guide for franchise owners and commissioners for the future strategic planning.
\end{abstract}

Keywords: Professional Sports Franchises; Performance Measures; Comparative Team Strength; Rank-Power Distribution, Zipf's Law; Pareto Principle

\section{INTRODUCTION}

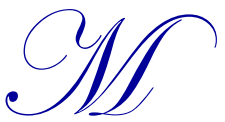

ajor professional sports teams are nowadays complex businesses, intrinsically concerned with matters of economics and finance. Performance on the field is inextricably linked to financial measures, such as payroll of the players (Hall, Szymanski \& Zimbalist, 2002) and expenses of the club (Avgerinou, Giakoumatos, Konstantinakos \& Mountakis, 2006).

The academic field of professional team sports economics dates back to the middle 1950s. Although a lot has been written ever since, Avgerinou (2007) selected three articles, which are seminal in the economics of sports: Rottenberg (1956), Neale (1964), and Sloane (1971). Rottenberg (1956) posited that the closer the competition between teams, the greater interest in the sport and, therefore, the greater the likelihood of total attendance. Neale (1964) suggested that the sports industry differs from other industry in that monopoly is not profitable because of the joint production of the sports product. He also described varying sources of demand for the sporting competition. Sloan (1971) argued that team owner may not be profit maximizers, but rather try to maximize their utility, which is a function of playing success; average attendance; competitive balance of the league, and a higher after-tax profit than the minimum acceptable.

There have been many studies in the sports management literature. However, their perspectives are too narrow to see the whole view of how each franchise operates. For example, Hansen \& Gauthier (1989) studied sport attendance in professional team sports; Nourayi (2006) for the profitability of the NBA franchise; Scully (1974) for pay and performance in the MLB; Leeds, Allmen \& Matheson (2018) for team performance measures in the MLB; Juravich, Salaga \& Babiak (2017) for the management of human resources in the NBA.

North America is home to four preeminent professional franchises: MLB (Major League Baseball) has 30 teams; NBA (National Baseball Association) has 30 teams, NFL (National Football League) has 32 teams, and NHL (National Hockey League) has 30 teams. But performance of each team and each franchise varies greatly.

The objective of this paper is to picture the performance disparities in the major professional sports franchises in the North America and to show the comparative strength of each team in a franchise and comparative strength among 
franchises. In line with above mentioned sports economists' suggestions, four performance measures are chosen for our study: attendance, revenue, payroll, and profit. Profits are simplified by taking the difference between a team's revenue and payroll. All of these factors come down to a team's willingness and desire to win, compete and improve. Refer to Hoye, Smith, Nicholson \& Stewart (2018) for more financial management function in sport organization.

This paper is organized in six sections. Section 2 shows box-plots to explore performance data graphically. The boxplot illustrates the data distribution pattern (positively or negatively skewed), as well as the degree of data disperse graphically. Section 3 introduces the rank-power distribution, which was utilized to rank the size of cities, length of rivers, etc. This distribution curves visualize the relative strength of dominant teams and the relative weakness of dominated teams. Section 4 makes the rank-power analyses across franchises. Section 5 makes the rank-power analyses within franchises. Section 6 offers concluding remarks.

All performance data in this study is taken from the 2011 regular season and is given in Appendix B.

\section{BOX-PLOT ANALYSIS}

Box-plots are informative graphs (Iversen \& Gergen, 1997). They show the extreme values (maximum and minimum) as well as mid-range values $\left(25^{\text {th }}, 50^{\text {th }}\right.$ and $75^{\text {th }}$ percentiles). Box-plots are particularly useful to compare the data from several groups simultaneously.

Figure 1-A shows the box- plots of attendances for four franchises. First, we notice that the MLB commands almost 4 to 5 times more median attendance than the other three leagues. Teams that bring in the lowest attendance for MLB are much higher than any team in any other sport. One of reasons for the MLB having a much larger attendance may be because of the number of games played in one season: the MLB has 162 games; the NBA and the NHL have 82 games each; the NFL has 16 games, but the MLB has larger margin between largest and smallest attendances while other leagues have a smaller margin. Accordingly, the NFL has the largest fan attendance per game.

Figure 1-B shows box-plots for the revenue category. All four professional sports reveal large differences between minimums and maximums. Furthermore, they reveal positively skewed distributions, which indicate large differences among top tier (highest $25 \%$ ) teams, and relatively small differences among bottom tier (lowest $25 \%$ ) teams.

Figure 1-C shows box-plots for the payroll category. The MLB is the most spread out when it comes to payroll. The MLB has a team, which pays the highest payroll, but the NFL has highest median payroll, and the NHL has the lowest median payroll.

Figure 1-D shows box-plots for the profit category. Profits along all leagues are extremely widespread. The NFL has a team which earns highest profit among all US sports franchises. The MLB team with the highest revenue lost this honor to NFL due to large payroll. However, the NFL has the largest disparity in profit category. The NHL has the smallest disparity.

All four box plots have the positive skewed distribution, which indicate a larger deviation among upper teams and a smaller deviation among lower teams. Next, we need to investigate how strongly the top teams dominate the bottom teams.

\section{THE RANK-POWER DISTRIBUTION}

Scientists have observed a very interesting pattern of distributions of city sizes, sizes of business, the length of rivers, the frequencies of word usage, and wealth among individuals. That is, small occurrences in nature are extremely common, whereas large instances are extremely rare. For example, long rivers are very few, short rivers are many. Actually there are only 8 rivers in the world that extend more than 3000 miles in length. This power regularity is called the power-law distribution or Zipf's law (Zipf, 1949; Adamic, 2020).

The rank-power distribution is the distribution of size by rank, in deceasing order of size. For example, if a data set consists of team revenues (in million dollars) $\$ 180, \$ 201, \$ 175, \$ 272, \$ 427$, the rank size distribution is $(1,427),(2$, 272), (3, 201), (4, 180), (5, 175). 
While following the idea of the rank-size distribution, we made two modifications to accommodate different units (\$, number of people) in the data and large number of entries (i.e., number of teams). First, we introduce the relative figures of each team compared with the figure of the leader. That is, the ratio between the team with the highest figures in each category to the rest of the teams in the league. The rank-power of the $i^{\text {th }}$ ranked team is defined as $R_{i}=X_{i} / X_{1}$, $0<\mathrm{R}_{\mathrm{i}} \leq 1, \mathrm{I}=1, \ldots, \mathrm{n}$ where $\mathrm{X}_{1}=$ amount of first rank team, $\mathrm{X}_{\mathrm{i}}=$ amount of the $\mathrm{i}^{\text {th }}$ rank team, $\mathrm{n}=$ number of teams in franchise. Second, we draw a line graph by connecting $n$ points of $\left(I, R_{i}\right)$.

\section{RANK-POWER ANALYSES ACROSS FRANCHISES}

Figure 2-A shows the rank-power distributions in attendance from each league. Attendance relationships among teams are very similar in NBA, NFL, and NHL, but the MLB has a greater difference between highest and lowest attendance in the stadium per season. One of the reasons is that the MLB has 162 games per season, which is more than double the number of games played by other leagues.

Figure 2-B shows rank-power curves in revenue from four franchises. Sharp reduction in revenue is observed in all the leagues after the top two or three teams. Revenues across the leagues have very similar relationships with most teams being around $40 \%$ and $60 \%$ of their league's leader. The MLB has the greatest difference with the lowest revenues around $30 \%$ that of the league leader. The NFL has the smallest difference with the league's lowest only $50 \%$ that of the league leader.

Figure 2-C shows rank-power curves in payroll across franchises. Payroll distributions across the leagues are very close, but once again the MLB is an odd league. The NFL, NHL, and NBA all have minimum payroll ratios between $40 \%$ and $60 \%$, but the MLB has a team with a payroll that is less than $20 \%$ that of the league's leader. Actually the highest and lowest ratio is 5.7. This is partly due to the regulations among the leagues; the MLB does not have a minimum payroll cap.

Figure 2-D shows rank-power distributions in profit among league members. In the profits category all sharp reduction is observed after the top 4 to 5 teams. Both the MLB and NFL are a close distribution and so are the NBA and NHL. Profits from the MLB and NFL are greater than those from NBA and NHL. Most teams in the NFL and MLB have profits between $40 \%$ and $60 \%$ that of their league leaders. While most teams in the NBA and NHL are more spread out and are between $10 \%$ and $50 \%$ of their league leaders.

\section{RANK-POWER ANALYSES WITHIN FRANCHISES}

Figure 3-A shows relative performance power in the MLB league. Revenue, payroll and profit have a similar downturn pattern. But the attendance shows a relatively small variation among teams. Payroll across the MLB is spread out more than other categories, with the weakest team only posting $18 \%$ that of the league leader. Attendance has a gradual reduction up to $40 \%$.

Figure 3-B shows relative performance power in the NHL league. It reveals attendance and payroll graphs have a very similar shape, which indicates teams' total payroll were in proportion to total attendance. Teams within the NHL do not have equally proportioned profits; the majority of teams are between $10 \%$ and $50 \%$ of the league leader due to high payroll.

Figure 3-C shows relative performance power in the NFL league. Partly due to small number of games within a single season, attendance among the NFL teams is quite high and consistent across the league. Majority of teams are between $60 \%$ and $90 \%$ that of the league leader. Revenues are extremely consistent with the majority between $50 \%$ and $60 \%$. A majority of the NFL teams have payrolls between $60 \%$ and $80 \%$, this shows an area of more balance within the league. Profits in the NFL are more spread out; the weakest team is near $20 \%$ that of the league leader and a majority of the teams are between $40 \%$ and $60 \%$ largely due to high payroll.

Figure 3-D shows the relative performance power in the NBA league. Attendance in the NBA is consistently high; there are not any extremely weak teams in this category. The entire league is above $60 \%$ that of the league leader. The revenues are a different story in the NBA, majority of the league is between $40 \%$ and $60 \%$ of the league leader. There 
are only a few teams above $60 \%$ in the revenue category. Payrolls are also spread out in the NBA with a majority between $60 \%$ and $80 \%$ that of the league leader. However, profits are most spread out among teams. The weakest team makes around $10 \%$ of the league leader.

\section{CONCLUDING REMARKS}

We have employed the box-plot and the rank power distribution diagrams to extract hidden messages from the raw performance data. These analyses rendered qualitative rather than quantitative conclusions with the least amount of analytical study.

The box-plot analyses offer an overall view of team performance. Attendance box- plots clearly shows why baseball is called the most popular sport in the United States (see Figure 1-A). In general, there existed large disparities in performance measures among leagues. Especially, the disparities in profits among top teams are larger than the other categories. How to minimize disparities among teams? It is a strategic issue for the franchise commissioners.

The rank-power analysis renders the relative standing for each team power (or strength). First, Figures 3-A, B, C and $\mathrm{D}$ show that weaker teams in each franchise do not make high profits even with the high attendance and high revenue. Why? The top management of weaker teams need to investigate the reason.

Second, we have observed most rank-power distribution curves take "L" shape, which has very steep reduction in the beginning, medium reduction in the middle, and shallow in the end. In other word, a few mighty teams strongly dominate many weak teams.

Vilfredo Pareto in 1897 found that a wealth was concentrated in the hands of a few and poverty in the hands of the many while studying the patterns of wealth in England (Bak, 1996; Russell-Walling, 2008). Hence, we can draw similar conclusions as Pareto made 120 years ago: (1) A few teams that score very high (significant few), (2) A medium number of teams with middle-of-the-road scores, (3) A large number of teams that score very low (trivial many).

We have seen that the box-plot and the rank power distribution diagram are essential tools to extract hidden messages from the raw performance data. We could draw qualitative rather than quantitative conclusions. They can be a useful guide for franchise owners and commissioners for future planning such as revenue sharing, player recruits, salary cap, sustainability plan, etc. to reduce the disparity among teams. Considering that the majority of sport economics articles are quantitative (94.1\%) (Mondello \& Pedersen, 2003), our qualitative approach would complement the uncovered area of performance analysis.

\section{ACKOWLEDGEMENTS}

Authors are grateful to Matthew Kinsley for drawing figures in this article.

\section{AUTHOR BIOGRAPHIES}

K. Paul Yoon is Professor of Decision Sciences at Fairleigh Dickinson University. His B.S. degree is from Seoul National University, South Korea, and his M.S. and Ph.D. degrees are from Kansas State University. He is a co-creator of TOPSIS, a classical multiple attribute decision making method.

Mohammad Sedaghat is a Professor in the Department of Marketing, Information Systems and Decision Sciences at Fairleigh Dickinson University. He obtained his Ph.D. in Operations Research from Polytechnic University, New York. His research interests include Queuing theory and stochastic processes. Email: sedaghat@fdu.edu (Corresponding author) 


\section{REFERENCES}

Adamic, L.A. (2020). Zipf, power-laws, and Pareto - a ranking tutorial. Retrieved from https://www.hpl.hp.com/research/idl/papers/ranking/ranking.html.

Avgerinou, V. (2007). The economics of professional team sports: content, trend and future development, Sport Management International Journal, 3(1), 5-17.

Avgerinou, V., Giakoumatos, S., Konstantinakos, P. \& Mountakis, K. (2006). An economic approach of league position in Greek football, ELLEDA Conference Proceedings, Thesalonki 2006.

Bak, P. (1996). How Nature works: The Science of Self-Organized Criticality, New York: Springer-Verlag.

Hall, S., Szymanski, S., \& Zimbalist, A. (2002). Testing causality between team performance and payroll, the cases of major league baseball and English soccer. Journal of Sports Economics, 3(3), 149-168.

Hansen H. \& Gauthier, R. (1989). Factor affecting attendance at professional sports Events. Journal of Sport Management, 3(1), 15-32.

Hoye, R., Smith, A., Nicholson, M. \& Stewart, B. (2018). Sport Management: Principles and Applications, New York: Routledge.

Iversen, G.R., \& Gergen, M. (1997). Statistics: The Conceptual Approach. New York, NY: Springer-Verlag.

Juravich, M., Salaga, S. \& Babiak, K. (2017). Upper echelons in professional sport. Journal of Sport Management, 31(5), 466479.

Leeds, M. A., Allmen, P.V. \& Matheson, V.A. (2018). The Economics of Sports (6 ${ }^{\text {th }}$ Edition), New York: Routledge.

Mondello, M. J. \& Pedersen, P. M. (2003). A content analysis of the journal of sports economics. Journal of Sports Economics, 4(1), 64-73.

Neale, W. (1964). The peculiar economics of professional sports. Quarterly Journal of Economics, 78(1), 1-14.

Nourayi, M. (2006). Profitability in professional sports and benchmarking. Benchmarking: An International Journal, 13(3), 252271.

Rottenberg, S. (1956). The baseball player's labor market. Journal of Political Economy, 64(3), 241-258.

Russell-Walling, E. (2008). 50 Management Ideas You Really Need to Know. London, UK: Quercus.

Scully, G.W. (1974). Pay and performance in major league baseball. The American Economic Review, 64(6), 915-930.

Sloane, P. (1971). The economics of professional football: the football club as a utility maximizer. Scottish Journal of Political Economy, 17, 121-146.

Zipf, G.K. (1949). Human Behavior and Principles of Least Effort, Cambridge, Mass: Addison-Wesley. 
APPENDIX A

Figure 1-A. Box-Plots for Attendance

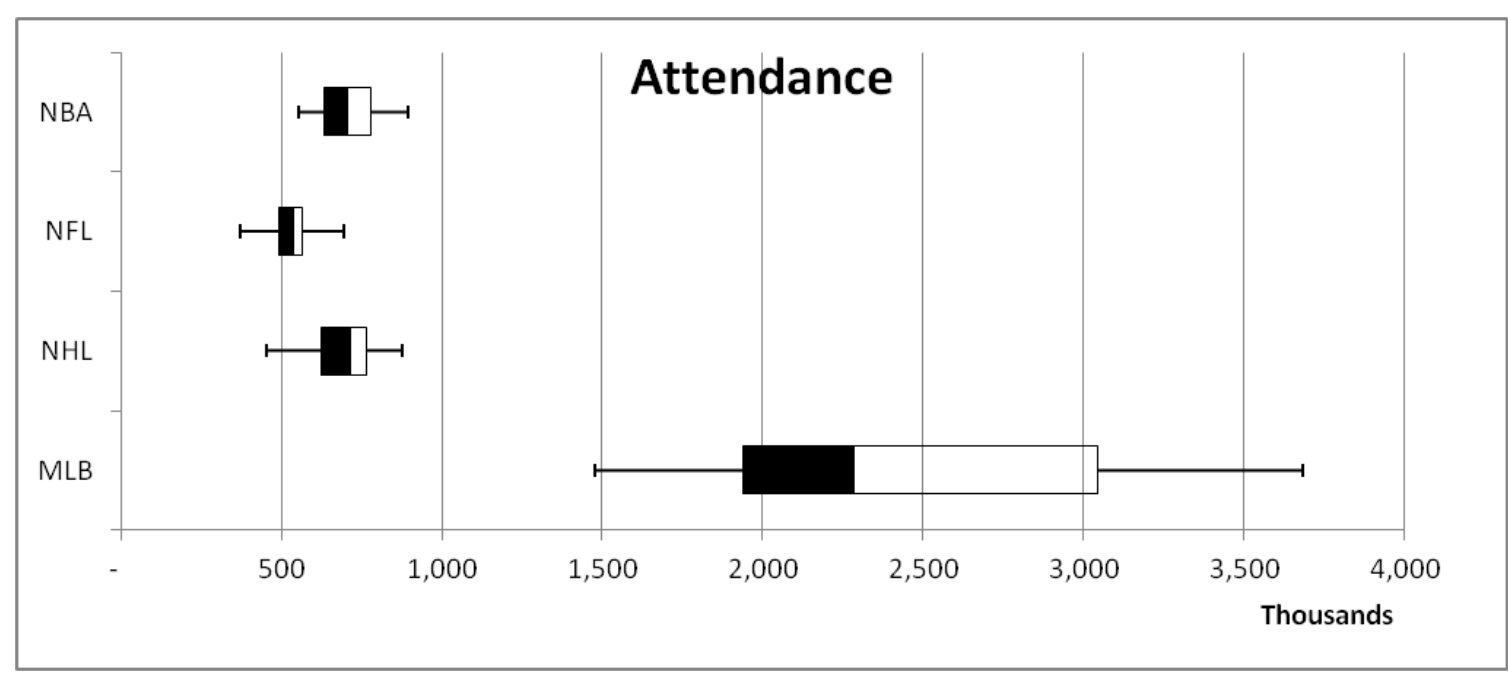

Figure 1-B. Box Plots for Revenue

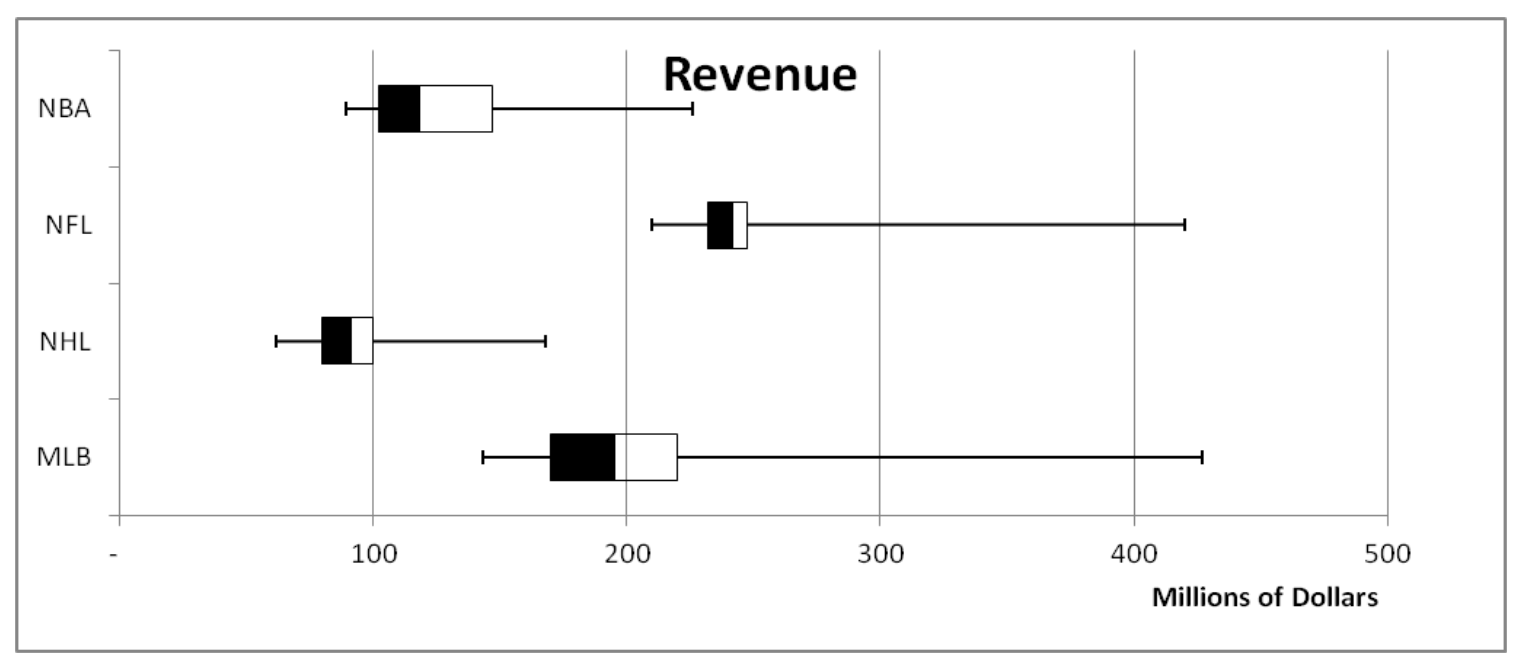


Figure 1-C. Box Plots for Payroll

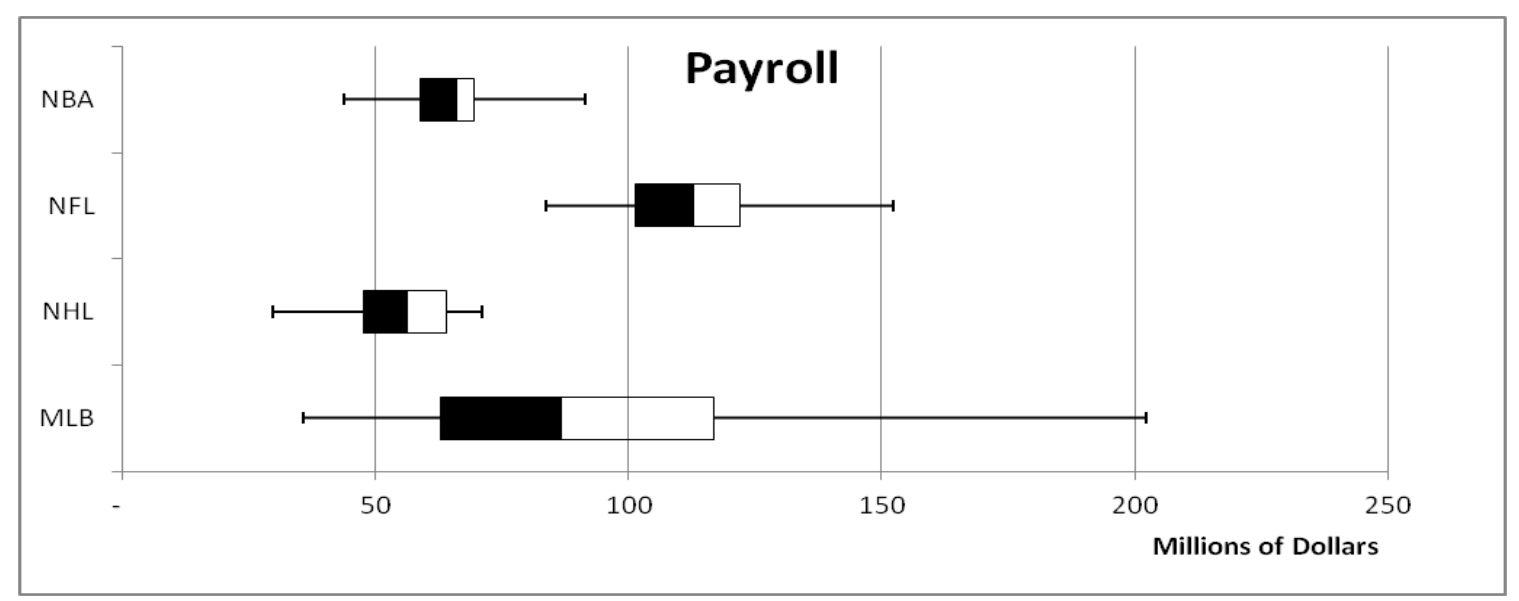

Figure 1-D. Box Plots for Profit

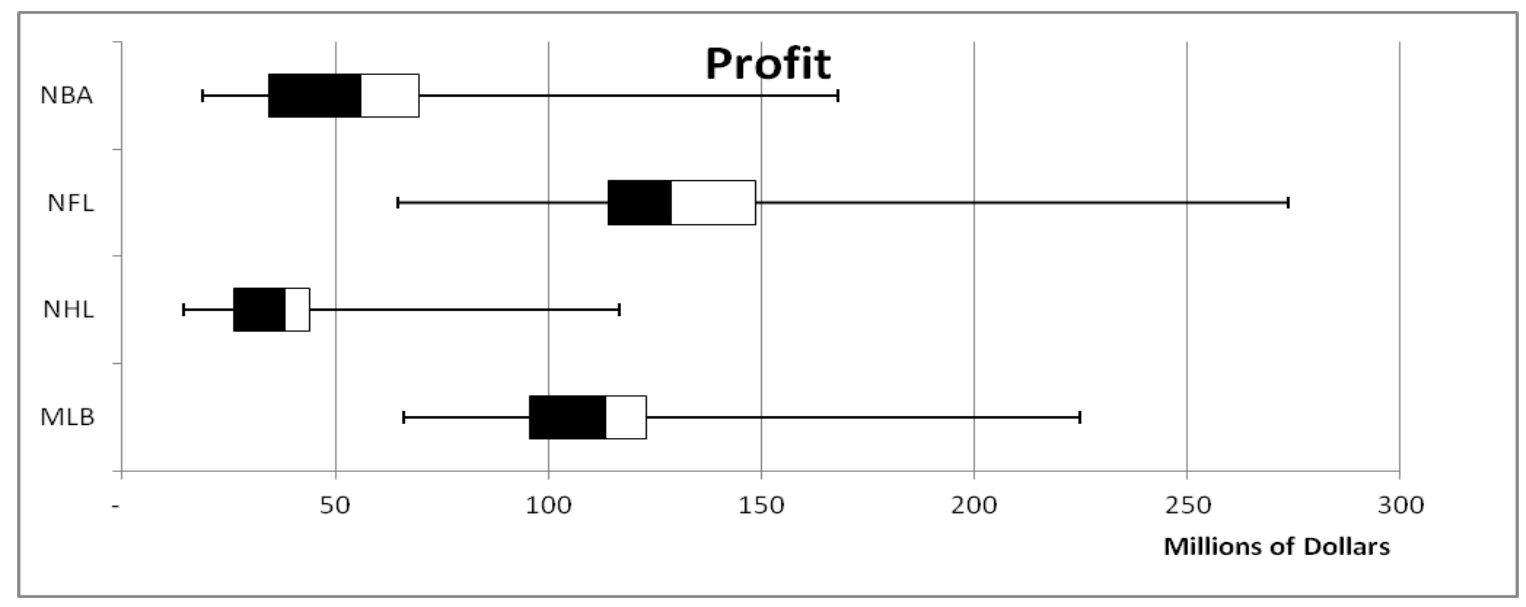


Figure 2-A. Rank - Power Curves for Attendance

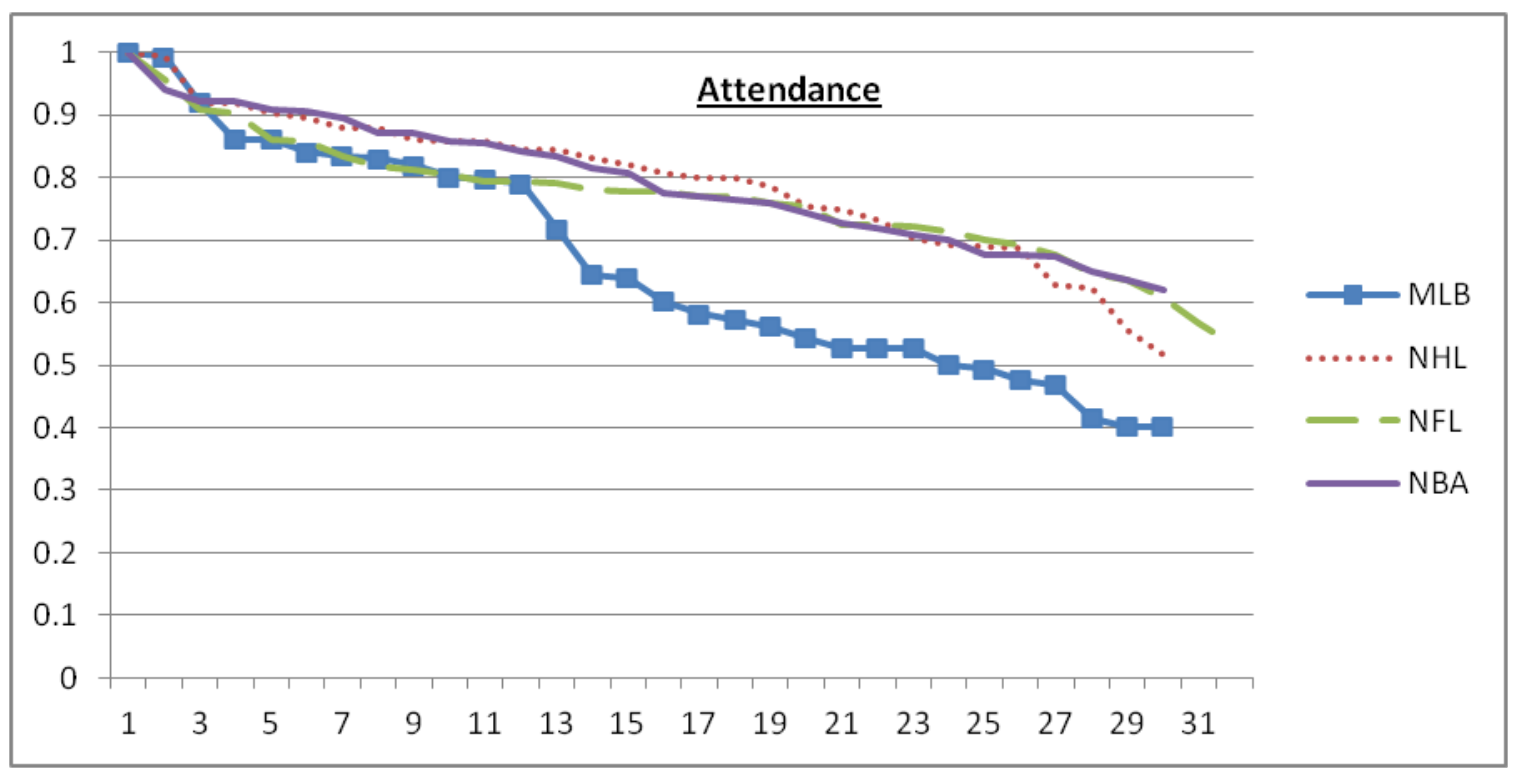

Figure 2-B. Rank - Power Curves for Revenue

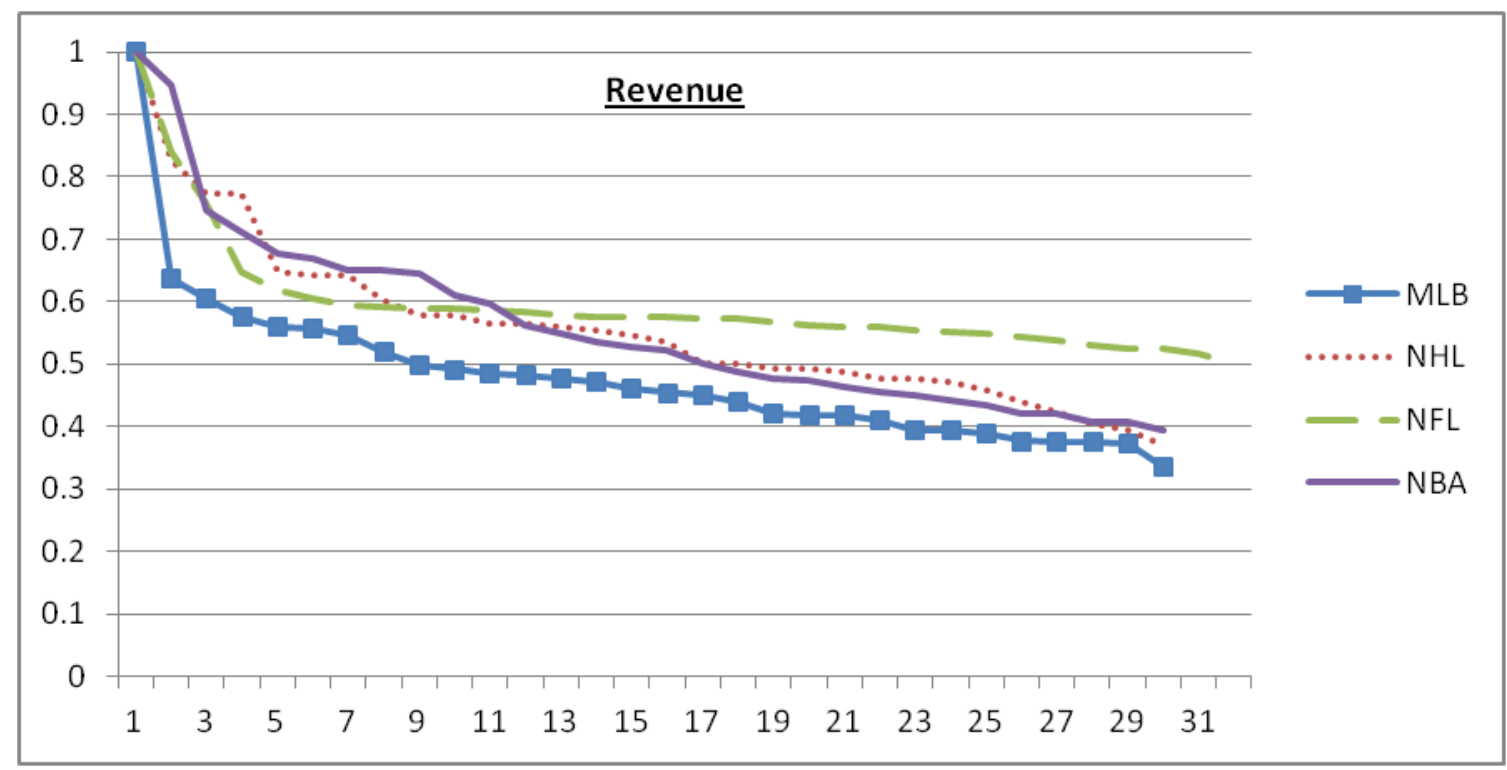


Figure 2-C. Rank - Power Curves for Payroll

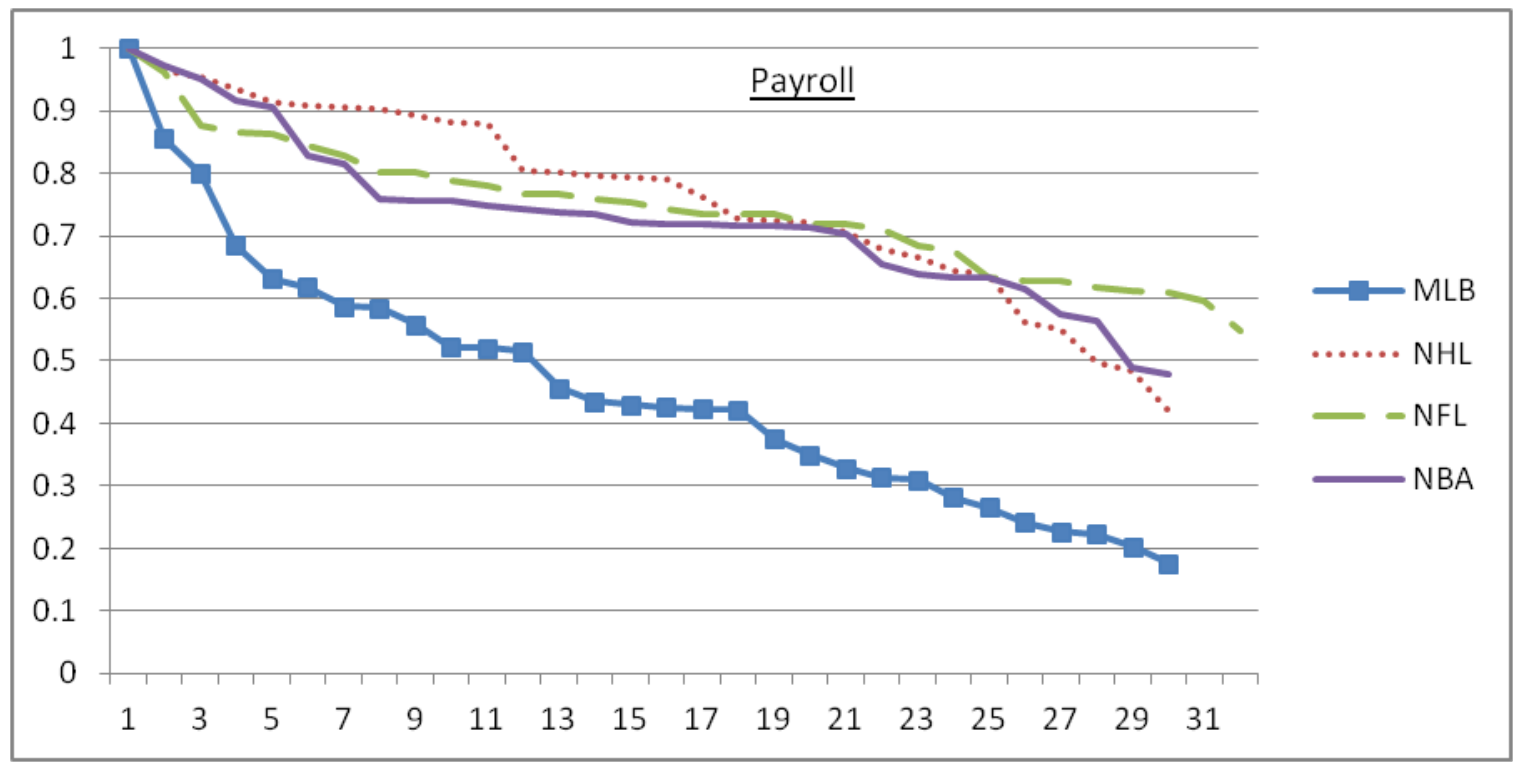

Figure 2-D. Rank - Power Curves for Profit

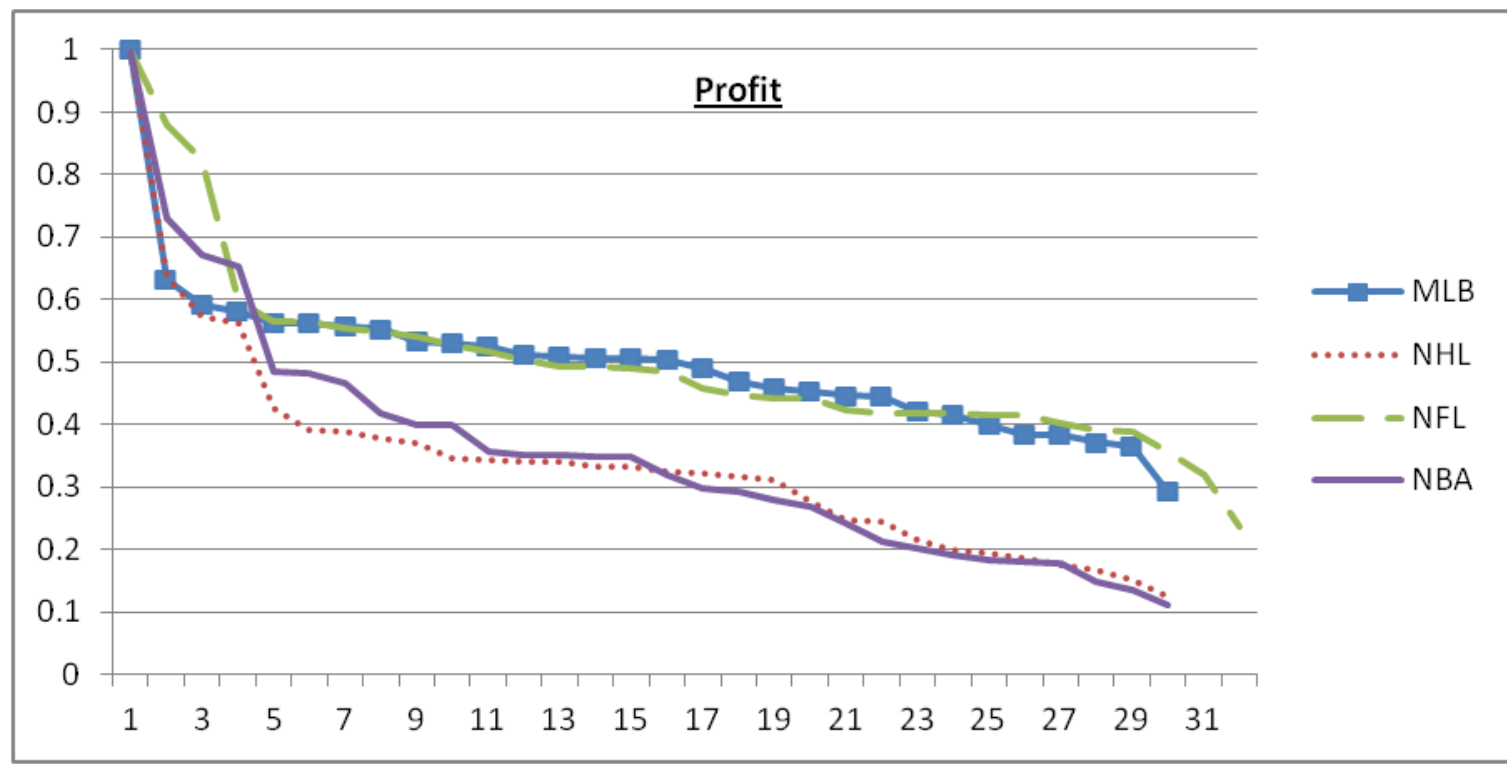


Figure 3-A. Rank - Power Curves for MLB

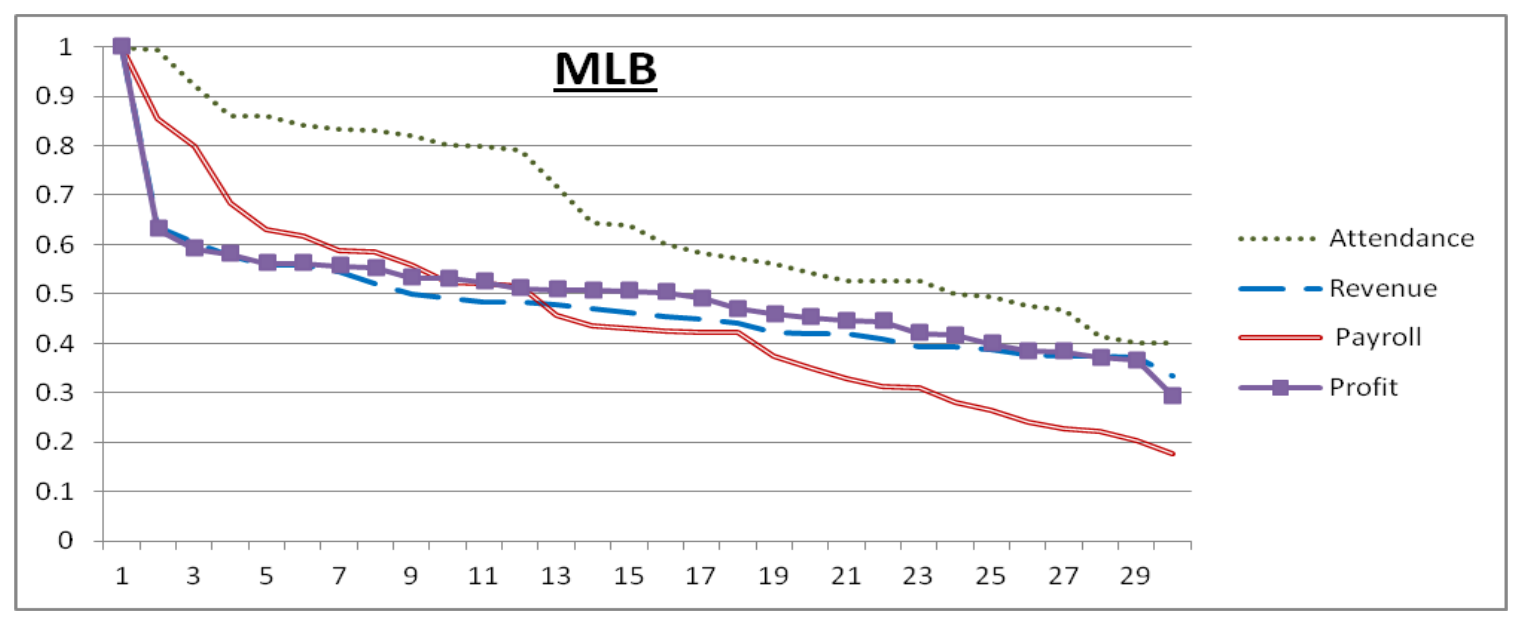

Figure 3-B. Rank - Power Curves for NHL

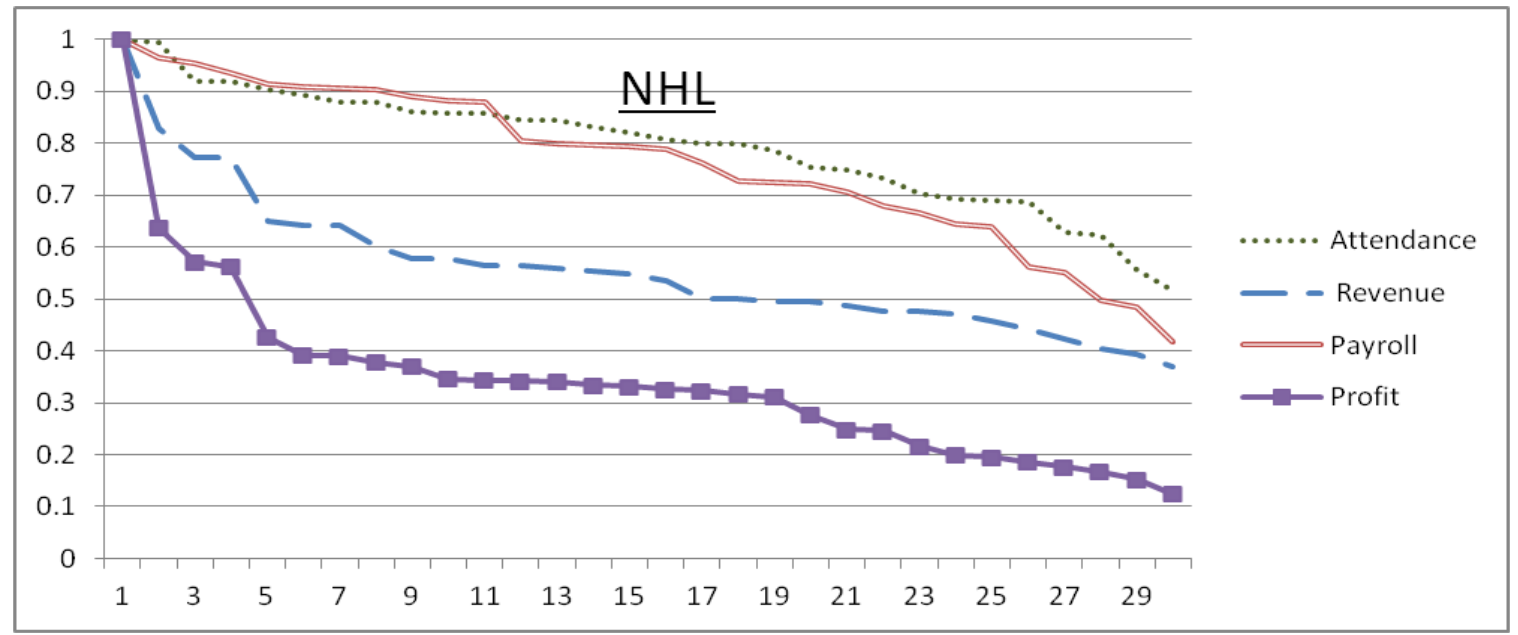


Figure 3-C. Rank - Power Curves for NFL

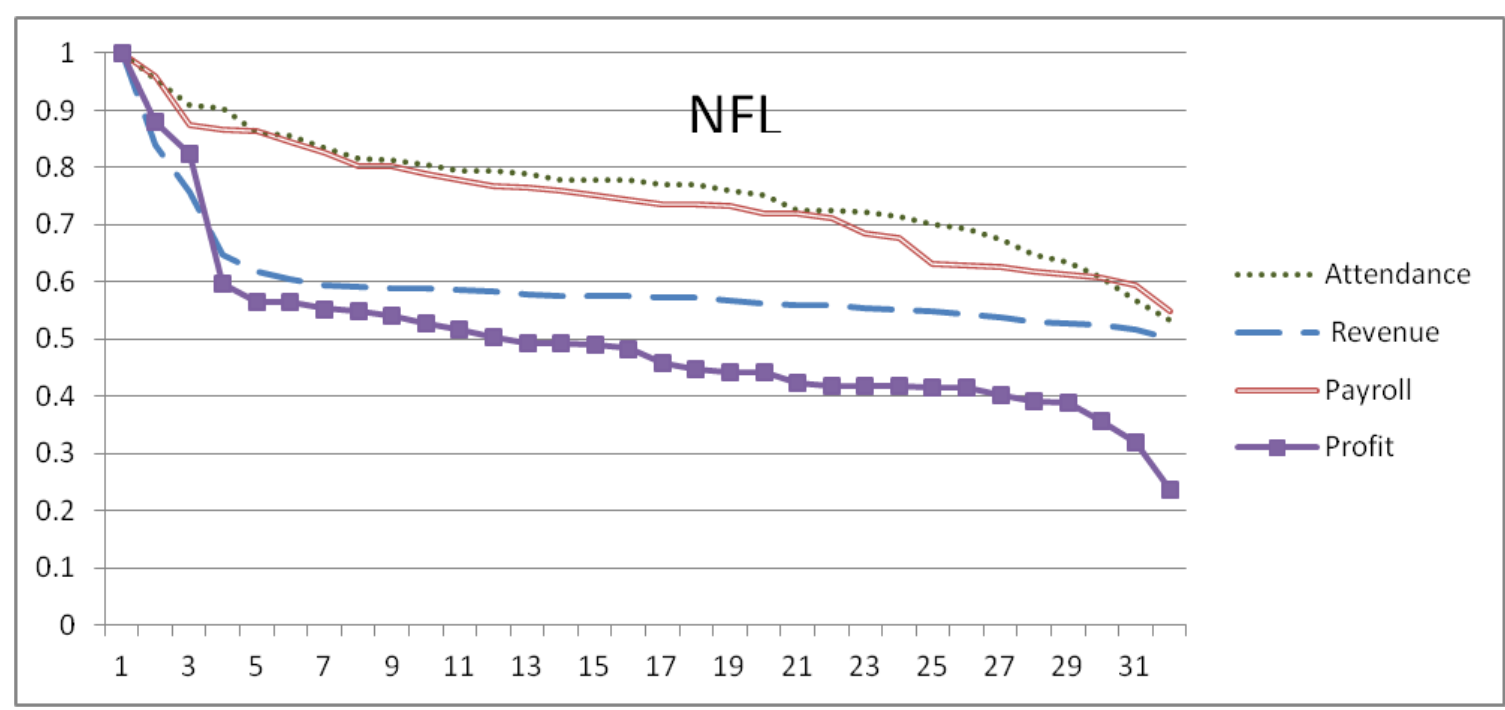

Figure 3-D. Rank - Power Curves for NBA

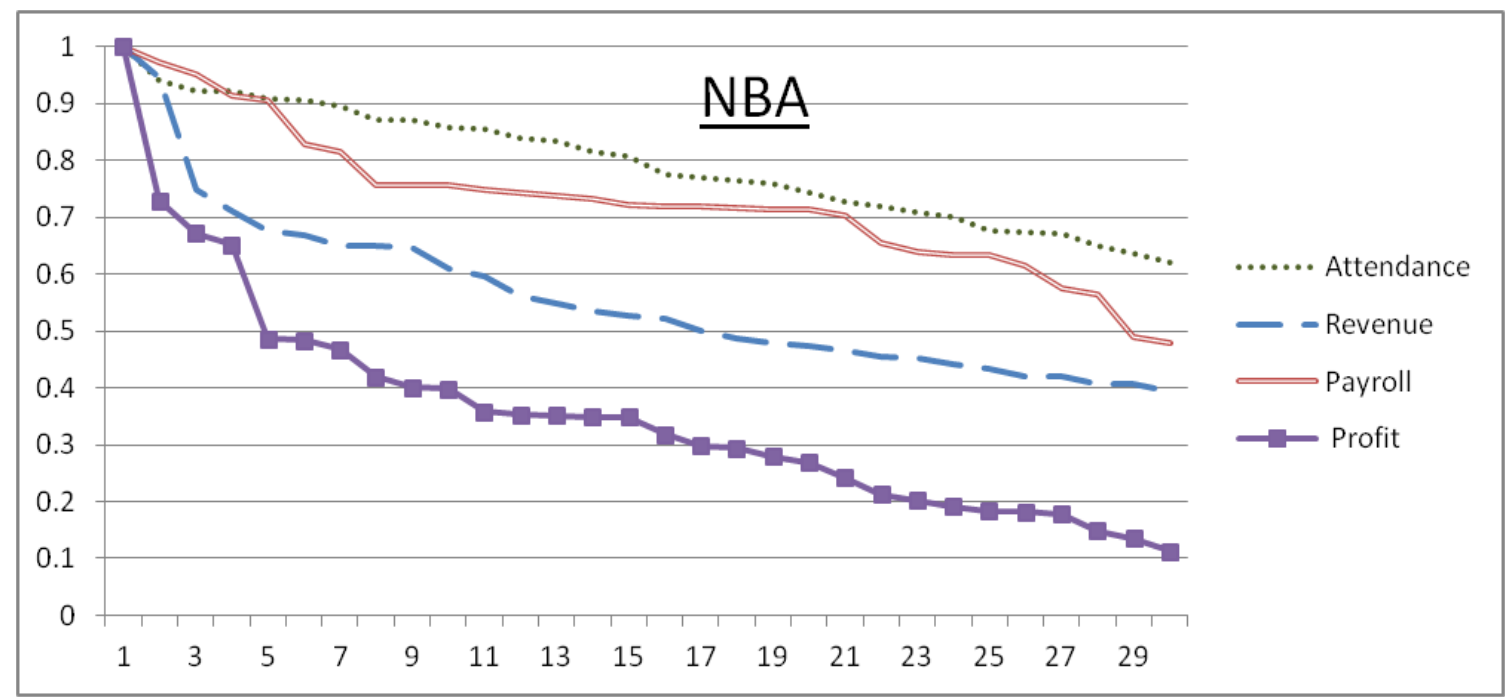




\section{APPENDIX B}

Performance Data for MLB

\begin{tabular}{|c|c|c|c|c|}
\hline Team & Attendance & Revenue & Payroll & Profit \\
\hline Arizona Diamondbacks & $2,105,432$ & $\$ 180,000,000$ & $\$ 53,639,833$ & $\$ 126,360,167$ \\
\hline Atlanta Braves & $2,373,940$ & $\$ 201,000,000$ & $\$ 87,002,692$ & $\$ 113,997,308$ \\
\hline Baltimore Orioles & $1,755,461$ & $\$ 175,000,000$ & $\$ 85,304,038$ & $\$ 89,695,962$ \\
\hline Boston Red Sox & $3,054,001$ & $\$ 272,000,000$ & $\$ 161,762,475$ & $\$ 110,237,525$ \\
\hline Chicago Cubs & $3,017,966$ & $\$ 258,000,000$ & $\$ 125,047,329$ & $\$ 132,952,671$ \\
\hline Chicago White Sox & $2,001,117$ & $\$ 210,000,000$ & $\$ 127,789,000$ & $\$ 82,211,000$ \\
\hline Cincinnati Reds & $2,213,588$ & $\$ 179,000,000$ & $\$ 75,947,134$ & $\$ 103,052,866$ \\
\hline Cleveland Indians & $1,840,835$ & $\$ 168,000,000$ & $\$ 48,776,566$ & $\$ 119,223,434$ \\
\hline Colorado Rockies & $2,909,777$ & $\$ 188,000,000$ & $\$ 88,148,071$ & $\$ 99,851,929$ \\
\hline Detroit Tigers & $2,642,045$ & $\$ 192,000,000$ & $\$ 105,700,231$ & $\$ 86,299,769$ \\
\hline Florida Marlins & $1,477,462$ & $\$ 143,000,000$ & $\$ 56,944,000$ & $\$ 86,056,000$ \\
\hline Houston Astros & $2,067,016$ & $\$ 197,000,000$ & $\$ 70,694,000$ & $\$ 126,306,000$ \\
\hline Kansas City Royals & $1,724,450$ & $\$ 160,000,000$ & $\$ 35,712,000$ & $\$ 124,288,000$ \\
\hline Los Angelos Angels & $3,166,321$ & $\$ 222,000,000$ & $\$ 138,543,166$ & $\$ 83,456,834$ \\
\hline Los Angelos Dodgers & $2,935,139$ & $\$ 246,000,000$ & $\$ 104,188,999$ & $\$ 141,811,001$ \\
\hline Milwaukee Brewers & $3,071,373$ & $\$ 179,000,000$ & $\$ 85,497,333$ & $\$ 93,502,667$ \\
\hline Minnesota Twins & $3,168,116$ & $\$ 213,000,000$ & $\$ 112,737,000$ & $\$ 100,263,000$ \\
\hline New York Mets & $2,352,596$ & $\$ 233,000,000$ & $\$ 118,847,309$ & $\$ 114,152,691$ \\
\hline New York Yankees & $3,653,680$ & $\$ 427,000,000$ & $\$ 202,275,028$ & $\$ 224,724,972$ \\
\hline Oakland Athletics & $1,476,791$ & $\$ 161,000,000$ & $\$ 66,536,500$ & $\$ 94,463,5000$ \\
\hline Philadelphia Phillies & $3,680,718$ & $\$ 239,000,000$ & $\$ 172,976,379$ & $\$ 66,023,621$ \\
\hline Pittsburg Pirates & $1,940,429$ & $\$ 160,000,000$ & $\$ 45,047,000$ & $\$ 114,953,000$ \\
\hline San Diego Padres & $2,143,018$ & $\$ 159,000,000$ & $\$ 45,869,140$ & $\$ 113,130,860$ \\
\hline San Francisco Giants & $3,387,303$ & $\$ 238,000,000$ & $\$ 118,198,333$ & $\$ 119,801,667$ \\
\hline Seattle Mariners & $1,939,421$ & $\$ 204,000,000$ & $\$ 86,110,600$ & $\$ 117,889,400$ \\
\hline St. Louis Cardinals & $3,093,954$ & $\$ 207,000,000$ & $\$ 105,433,572$ & $\$ 101,566,428$ \\
\hline Tampa Bay Rays & $1,529,188$ & $\$ 166,000,000$ & $\$ 41,053,571$ & $\$ 124,946,429$ \\
\hline Texas Rangers & $2,946,949$ & $\$ 206,000,000$ & $\$ 92,299,264$ & $\$ 113,700,736$ \\
\hline Toronto Blue Jays & $1,818,103$ & $\$ 168,000,000$ & $\$ 62,567,800$ & $\$ 105,432,200$ \\
\hline Washington Nationals & $1,940,478$ & $\$ 194,000,000$ & $\$ 63,442,928$ & $\$ 130,557,072$ \\
\hline
\end{tabular}

Source: $\mathrm{http}: / /$ espn.go.com $/ \mathrm{mlb} / \mathrm{attendance}$

Source: http://www.forbes.com/lists/2011/33/baseball-valuations-11_land.html

Source: http://content.usatoday.com/sportsdata/baseball/mlb/salaries/team 
Performance Data for NHL

\begin{tabular}{|c|c|c|c|c|}
\hline Team & Attendance & Revenue & Payroll & Profit \\
\hline Anehiem Ducks & 604,283 & $\$ 94,000,000$ & $\$ 53,977,500$ & $\$ 40,022,500$ \\
\hline Boston Bruins & 702,600 & $\$ 108,000,000$ & $\$ 64,822,500$ & $\$ 43,177,500$ \\
\hline Buffalo Sabres & 756,568 & $\$ 79,000,000$ & $\$ 56,255,000$ & $\$ 22,745,000$ \\
\hline Calgary Flames & 771,560 & $\$ 95,000,000$ & $\$ 66,312,500$ & $\$ 28,687,500$ \\
\hline Carolina Hurricanes & 656,611 & $\$ 82,000,000$ & $\$ 45,735,000$ & $\$ 36,265,000$ \\
\hline Chicago Blackhawks & 878,356 & $\$ 108,000,000$ & $\$ 62,502,857$ & $\$ 45,497,143$ \\
\hline Colombus Blue Jackets & 546,350 & $\$ 77,000,000$ & $\$ 56,440,000$ & $\$ 20,560,000$ \\
\hline Colorado Avalanche & 607,650 & $\$ 84,000,000$ & $\$ 39,872,500$ & $\$ 44,127,500$ \\
\hline Dallas Stars & 617,997 & $\$ 97,000,000$ & $\$ 47,310,000$ & $\$ 49,690,000$ \\
\hline Detroit Red Wings & 806,892 & $\$ 130,000,000$ & $\$ 64,325,000$ & $\$ 65,675,000$ \\
\hline Edmonton Oilers & 690,399 & $\$ 83,000,000$ & $\$ 45,305,000$ & $\$ 37,695,000$ \\
\hline Florisa Panthers & 643,116 & $\$ 74,000,000$ & $\$ 35,302,500$ & $\$ 38,697,500$ \\
\hline Los Angeles Kings & 741,404 & $\$ 92,000,000$ & $\$ 51,645,750$ & $\$ 40,354,250$ \\
\hline Minnesota Wild & 720,508 & $\$ 95,000,000$ & $\$ 56,035,000$ & $\$ 38,965,000$ \\
\hline Montreal Canadiens & 872,193 & $\$ 130,000,000$ & $\$ 63,245,833$ & $\$ 66,754,167$ \\
\hline Nashville Predators & 661,861 & $\$ 71,000,000$ & $\$ 51,387,500$ & $\$ 19,612,500$ \\
\hline New Jersey Devils & 605,803 & $\$ 97,000,000$ & $\$ 57,140,000$ & $\$ 39,860,000$ \\
\hline New York Islanders & 453,456 & $\$ 62,000,000$ & $\$ 29,727,500$ & $\$ 32,272,500$ \\
\hline New York Rangers & 742,432 & $\$ 139,000,000$ & $\$ 64,557,500$ & $\$ 74,442,500$ \\
\hline Ottowa Senators & 753,525 & $\$ 90,000,000$ & $\$ 50,083,333$ & $\$ 39,916,667$ \\
\hline Philadephia Flyers & 808,328 & $\$ 101,000,000$ & $\$ 64,108,000$ & $\$ 36,892,000$ \\
\hline Phoenix Coyotes & 487,543 & $\$ 66,000,000$ & $\$ 48,212,500$ & $\$ 17,787,500$ \\
\hline Pittsburgh Penquins & 729,628 & $\$ 93,000,000$ & $\$ 67,737,500$ & $\$ 25,262,500$ \\
\hline San Jose Sharks & 702,480 & $\$ 84,000,000$ & $\$ 62,321,662$ & $\$ 21,678,338$ \\
\hline St. Louis Blies & 785,150 & $\$ 80,000,000$ & $\$ 34,350,000$ & $\$ 45,650,000$ \\
\hline Tampa Bay Lightning & 708,022 & $\$ 80,000,000$ & $\$ 56,812,500$ & $\$ 23,187,500$ \\
\hline Toronto Maple Leafs & 793,522 & $\$ 168,000,000$ & $\$ 51,235,000$ & $\$ 116,765,000$ \\
\hline Vanvouver Canucks & 773,260 & $\$ 109,000,000$ & $\$ 70,975,000$ & $\$ 38,025,000$ \\
\hline Washington Capitols & 754,309 & $\$ 83,000,000$ & $\$ 68,425,000$ & $\$ 14,575,000$ \\
\hline Winnipeg Jets & 552,230 & $\$ 68,000,000$ & $\$ 39,035,750$ & $\$ 28,954,250$ \\
\hline
\end{tabular}

Source: http://espn.go.com/nhl/attendance//year/2011

Source: http://www.forbes.com/nhl-valuations/

Source: http://content.usatoday.com/sportsdata/hockey/nhl/salaries/team 
Performance Data for NFL

\begin{tabular}{|c|c|c|c|c|}
\hline Team & Attendance & Revenue & Payroll & Profit \\
\hline Arizona Cardinals & 502,197 & $\$ 236,000,000$ & $\$ 122,110,110$ & $\$ 113,889,890$ \\
\hline Atlanta Falcons & 542,800 & $\$ 231,000,000$ & $\$ 96,391,525$ & $\$ 134,608,475$ \\
\hline Baltimore Ravens & 596,817 & $\$ 235,000,000$ & $\$ 90,713,965$ & $\$ 144,286,035$ \\
\hline Buffalo Bills & 442,366 & $\$ 228,000,000$ & $\$ 113,364,927$ & $\$ 114,635,073$ \\
\hline Carolina Panthers & 580,965 & $\$ 247,000,000$ & $\$ 112,114,711$ & $\$ 134,885,289$ \\
\hline Chicago Bears & 497,561 & $\$ 254,000,000$ & $\$ 120,065,819$ & $\$ 133,934,181$ \\
\hline Cincinnati Bengals & 482,917 & $\$ 232,000,000$ & $\$ 109,727,880$ & $\$ 122,272,120$ \\
\hline Cleveland Browns & 528,933 & $\$ 242,000,000$ & $\$ 131,916,300$ & $\$ 110,083,700$ \\
\hline Dallas Cowboys & 696,377 & $\$ 420,000,000$ & $\$ 146,401,600$ & $\$ 273,598,400$ \\
\hline Denver Broncos & 599,264 & $\$ 250,000,000$ & $\$ 95,599,778$ & $\$ 154,400,222$ \\
\hline Detroit Lions & 450,286 & $\$ 210,000,000$ & $\$ 95,827,117$ & $\$ 114,172,883$ \\
\hline Green Bay Packers & 566,362 & $\$ 242,000,000$ & $\$ 94,018,300$ & $\$ 147,981,700$ \\
\hline Houston Texans & 568,643 & $\$ 272,000,000$ & $\$ 108,445,418$ & $\$ 163,554,582$ \\
\hline Indianapolis Colts & 535,802 & $\$ 248,000,000$ & $\$ 93,373,915$ & $\$ 154,626,085$ \\
\hline Jacksonville Jaguars & 504,262 & $\$ 220,000,000$ & $\$ 122,109,207$ & $\$ 97,890,793$ \\
\hline Kansas City Chiefs & 541,380 & $\$ 235,000,000$ & $\$ 83,623,776$ & $\$ 151,376,224$ \\
\hline Miami Dolphins & 541,959 & $\$ 247,000,000$ & $\$ 114,649,660$ & $\$ 132,350,340$ \\
\hline Minnesota Vikings & 470,009 & $\$ 221,000,000$ & $\$ 133,354,045$ & $\$ 87,645,955$ \\
\hline New England Patriots & 550,048 & $\$ 318,000,000$ & $\$ 92,734,120$ & $\$ 225,265,880$ \\
\hline New Orleans Saints & 560,304 & $\$ 245,000,000$ & $\$ 131,531,820$ & $\$ 113,468,180$ \\
\hline New York Giants & 632,156 & $\$ 241,000,000$ & $\$ 115,816,180$ & $\$ 125,183,820$ \\
\hline New York Jets & 628,768 & $\$ 238,000,000$ & $\$ 116,910,097$ & $\$ 121,089,903$ \\
\hline Oakland Raiders & 371,448 & $\$ 217,000,000$ & $\$ 152,389,371$ & $\$ 64,610,629$ \\
\hline Philadelphia Eagles & 553,152 & $\$ 260,000,000$ & $\$ 109,557,398$ & $\$ 150,442,602$ \\
\hline Pittsburgh Steelers & 504,669 & $\$ 243,000,000$ & $\$ 128,815,061$ & $\$ 114,184,939$ \\
\hline San Diego Chargers & 524,241 & $\$ 233,000,000$ & $\$ 111,813,340$ & $\$ 121,186,660$ \\
\hline San Fransisco 49ers & 488,124 & $\$ 226,000,000$ & $\$ 118,766,239$ & $\$ 107,233,761$ \\
\hline Seatle SeaHawks & 535,942 & $\$ 241,000,000$ & $\$ 102,985,710$ & $\$ 138,014,290$ \\
\hline St. Louis Rams & 423,383 & $\$ 223,000,000$ & $\$ 116,677,660$ & $\$ 106,322,340$ \\
\hline Tampa Bay Buccaneers & 394,513 & $\$ 246,000,000$ & $\$ 104,329,311$ & $\$ 141,670,689$ \\
\hline$\underline{\text { Tenessee Titans }}$ & 553,144 & $\$ 242,000,000$ & $\$ 126,017,443$ & $\$ 115,982,557$ \\
\hline Washington Redskins & 665,380 & $\$ 353,000,000$ & $\$ 111,963,684$ & $\$ 241,036,316$ \\
\hline
\end{tabular}

Source: http://espn.go.com/nfl/attendance

Source: http://www.forbes.com/lists/2010/30/football-valuations-10_NFL-Team-Valuations_Rank.html

Source: http://forums.chargers.com/archive/index.php/t-87259.html 
$\underline{\text { Performance Data for NBA }}$

\begin{tabular}{|c|c|c|c|c|}
\hline Team & Attendance & Revenue & Payroll & Profit \\
\hline Atlanta Hawks & 641,596 & $\$ 105,000,000$ & $\$ 69,371,770$ & $\$ 35,628,230$ \\
\hline Boston Celtics & 763,584 & $\$ 151,000,000$ & $\$ 83,790,759$ & $\$ 67,209,241$ \\
\hline Charlotte Bobcats & 649,694 & $\$ 98,000,000$ & $\$ 65,880,884$ & $\$ 32,119,116$ \\
\hline Chicago Bulls & 893,462 & $\$ 169,000,000$ & $\$ 56,237,705$ & $\$ 112,762,295$ \\
\hline Cleveland Cavaliers & 824,595 & $\$ 161,000,000$ & $\$ 51,572,807$ & $\$ 109,427,193$ \\
\hline Dallas Mavericks & 824,162 & $\$ 146,000,000$ & $\$ 87,056,125$ & $\$ 58,943,875$ \\
\hline Denver Nuggets & 692,968 & $\$ 113,000,000$ & $\$ 83,020,059$ & $\$ 29,979,941$ \\
\hline Detroit Pistons & 683,080 & $\$ 147,000,000$ & $\$ 65,917,821$ & $\$ 81,082,179$ \\
\hline Golden State Warriors & 766,398 & $\$ 119,000,000$ & $\$ 65,571,058$ & $\$ 53,428,942$ \\
\hline Houston Rockets & 663,839 & $\$ 153,000,000$ & $\$ 74,581,719$ & $\$ 78,418,281$ \\
\hline Indiana Pacers & 555,077 & $\$ 95,000,000$ & $\$ 64,368,421$ & $\$ 30,631,579$ \\
\hline Los Angelos Clippers & 727,462 & $\$ 102,000,000$ & $\$ 52,668,803$ & $\$ 49,331,197$ \\
\hline Los Angelos Lakers & 778,877 & $\$ 214,000,000$ & $\$ 91,569,659$ & $\$ 122,430,341$ \\
\hline Memphis Grizzlies & 600,687 & $\$ 92,000,000$ & $\$ 67,162,338$ & $\$ 24,837,662$ \\
\hline Miami Heat & 810,930 & $\$ 124,000,000$ & $\$ 65,356,624$ & $\$ 58,643,376$ \\
\hline Milwaukee Bucks & 631,910 & $\$ 92,000,000$ & $\$ 69,353,506$ & $\$ 22,646,494$ \\
\hline Minnesota Timberwolves & 624,960 & $\$ 95,000,000$ & $\$ 44,899,891$ & $\$ 50,100,109$ \\
\hline New Jersey Nets & 581,378 & $\$ 89,000,000$ & $\$ 58,539,907$ & $\$ 30,460,093$ \\
\hline New Orleans Hornets & 603,088 & $\$ 100,000,000$ & $\$ 66,133,816$ & $\$ 33,866,184$ \\
\hline New York Knicks & 808,879 & $\$ 226,000,000$ & $\$ 58,102,438$ & $\$ 167,897,562$ \\
\hline Oklahoma City Thunder & 744,068 & $\$ 118,000,000$ & $\$ 57,954,586$ & $\$ 60,045,414$ \\
\hline Orlando Magic & 777,852 & $\$ 108,000,000$ & $\$ 89,139,596$ & $\$ 18,860,404$ \\
\hline Philadelphia 76ers & 604,823 & $\$ 110,000,000$ & $\$ 69,360,246$ & $\$ 40,639,754$ \\
\hline Phoenix Suns & 720,249 & $\$ 147,000,000$ & $\$ 65,452,079$ & $\$ 81,547,921$ \\
\hline Portland Trailblazers & 840,924 & $\$ 127,000,000$ & $\$ 68,419,112$ & $\$ 58,580,888$ \\
\hline Sacremento Kings & 569,496 & $\$ 103,000,000$ & $\$ 43,798,401$ & $\$ 59,201,599$ \\
\hline San Antonio Spurs & 750,879 & $\$ 135,000,000$ & $\$ 68,129,480$ & $\$ 66,870,520$ \\
\hline Toronto Raptors & 679,208 & $\$ 138,000,000$ & $\$ 67,596,462$ & $\$ 70,403,538$ \\
\hline Utah Jazz & 799,982 & $\$ 121,000,000$ & $\$ 75,785,355$ & $\$ 45,214,645$ \\
\hline Washington Wizards & 688,466 & $\$ 107,000,000$ & $\$ 60,066,811$ & $\$ 46,933,189$ \\
\hline
\end{tabular}

Source: http://espn . go.com/nba/attendance//year/2011

Source: http://www.forbes.com/lists/2010/32/basketball-valuations-11_New-Orleans-Hornets_328959.html

Source: http://content.usatoday.com/sportsdata/basketball/nba/salaries/team 
NOTES 